Purdue University Purdue e-Pubs

Libraries Research Publications

$1-1-1992$

\title{
Willing to Provide but Unable to Support: The Dilemma of Smaller Depositories in an Electronic Era
}

Bert Chapman

Purdue University, chapmanb@purdue.edu

Follow this and additional works at: http://docs.lib.purdue.edu/lib_research

Chapman, Bert, "Willing to Provide but Unable to Support: The Dilemma of Smaller Depositories in an Electronic Era " (1992). Libraries Research Publications. Paper 68.

http://docs.lib.purdue.edu/lib_research/68

This document has been made available through Purdue e-Pubs, a service of the Purdue University Libraries. Please contact epubs@purdue.edu for additional information. 
Government Information Quarterly, Volume 9, Number 1, pages 81-87

\title{
Willing to Provide but Unable to Support: The Dilemma of Smaller Depositories in an Electronic Era
}

\author{
Bert Chapman
}

The increasing influence of government information in electronic format poses acute problems for smaller depositories facing financial and personnel shortages. These constraints will increase the dependence of smaller depositories on regional depositories and may compel the smaller institutions to reassess the viability of their depository status. This cumulative predicament will make some government information inaccessible to users of smaller depositories.

Recognition of this should be augmented by acceptance of the reality that existing Federal budgetary pressures, coupled with trends toward user fees in other sectors of librarianship, make free and unimpeded access to all government information an unrealistic public policy option. This, in turn, will increase the importance of regional depositories as clearinghouses for technical support and resource sharing and require selective depositories to place even greater emphasis on determining the government information of greatest relevance to their constituencies.

The increasing growth of information in electronic format affects our daily lives in areas ranging from personal finance to entertainment. This increasingly influential role played by electronic information both gratifies and concerns the library community and particularly government documents librarians. The pleasure of seeing this technological innovation providing enhanced user access to government information is diminished by limits on our ability to provide this information to our constituencies. This ability is hampered by the divergent formats carrying this information, financial and personnel constraints making it difficult to provide the equipment and instructional time necessary for effectual utilization of this information, and the apparent receptivity of the Government Printing Office (GPO) to modifying long-standing policy concerning free and unimpeded access to government information which has occurred in light of extant Federal budgetary constraints. These possible impediments are of acute concern to smaller depositories selecting 50\% or less of GPO's depository publications, such as Lamar University's Mary and John Gray Library. ${ }^{1}$

Lamar University is located in Beaumont, Texas, a city of approximately 120,000 located eighty-five miles northeast of Houston. Lamar's Beaumont campus has a combined undergraduate and graduate enrollment of nearly 12,000 students. Its principal curricular emphasis is scientific and technical with a doctoral program in engineering and several master's programs. Gray Library is a full state and selective U.S. depository taking nearly 28\% of GPO's offerings with particular emphasis on energy, geology, environmental protection, and other subjects of interest to the university, community, and region. The library's ability to provide services is influenced by the allocation it receives of the \$35.9 million appropriated to Lamar University-Beaumont by the state legislature for FY $1991{ }^{2}$

The Documents Department consists of one professional librarian who also performs general reference responsibilities, a library technical assistant, and two student assistants. Current U.S. government information in electronic format at Gray Library includes OCLC's CD-ROM versions of the Monthly Catalog and ERIC. Both share

Bert Chapman, Reference/Documents Librarian, Mary and John Gray Library, Lamar University, Beaumont, TX 77710. 
space on a Samsung SM-12SFA7 computer with a Hitachi TCDR3004 drive with audio and text capability in the Reference Department.

There is also a Packard Bell 286 computer with a Hitachi TCDR6000 drive with audio and text capability holding a commercial CD-ROM database. The documents librarian has requested that at least two CD-ROM workstations with multiserver capabilities be purchased for the Documents Department over the next five years in light of the increasing availability and influence of U.S. government information in electronic formats.

Unfortunately, the requests of the Documents Department, Gray Library, and all other Lamar University entities must contend for increasingly scarce Texas appropriations with other state-supported universities and with issues of pressing public policy concern, such as social services, prison construction, and judicially mandated elementary and secondary school finance reform. The intensity of this competition is augmented by Texas' estimated $\$ 4.7$ billion budget deficit and a tax structure dependent on sales taxes for over $60 \%$ of revenues available for public spending due to the absence of state personal and corporate income taxes. ${ }^{3}$

This budgetary shortfall plus the subsequent unwillingness of the governor, legislature, and public opinion to implement the requisite fiscal reforms, along with state procurement regulations, have deleteriously impacted overall library service in Texas. A report prepared for the Chairman of Texas' Senate Education Committee announced that public academic libraries experienced an \$8 million or 14\% reduction in state appropriations between FY 1986 and FY 1990 and that 16 of 34 surveyed institutions reported staff decreases during this period along with declining increases in annual acquisitions. ${ }^{4}$

This report also noted the negative impact such revenue reduction has had on library acquisition of emerging technology:

New information technology is beyond the reach of most institutions. Despite living in an information-rich environment, many institutions report being unable to use their enhancement funds for purchasing. upgrading, and replacing those systems that make information more accessible. ${ }^{5}$

The Education Committee's report also announced that surveyed libraries listed state requirements for soliciting bids for library automation systems and materials, as opposed to permitting the utilization of vendors granting significant discounts for nonbid purchases, as being one of the five state policies most disadvantageous to libraries. ${ }^{6}$

Such constrained state and institutional resources impede the ability of individual depositories to purchase the requisite equipment for accessing electronic information. A recent GPO assessment maintained that in budgeting for one CD-ROM a depository should estimate $\$ 1,200$ for a personal computer (PC), hard drive, and monochrome monitor, $\$ 200-\$ 300$ for a printer, and $\$ 650-\$ 750$ for a CD-ROM drive with projected costs of $\$ 2,050-\$ 2,300$ per workstation. Additional costs mentioned but not quantized by this assessment include workstation and drive security, furniture, subscription fees, paper, and ink. ${ }^{7}$

If online databases are utilized, telecommunications costs must also be taken into consideration. These can range from the long-distance costs necessary to access electronic bulletin boards, such as Project Hermes, ${ }^{8}$ to the $\$ 15-\$ 300$ per hour connect charges for online services cited in an influential Office of Technology Assessment (OTA) study of electronic information issues. ${ }^{9}$

Depositories choosing to select electronic formats must also consider factors, such as user education and computer literacy, staff training, and time allocation, in addition to finance and equipment. An Auburn University study made the following observations on how CD-ROM acquisition and usage affect library service:

Staff are called upon to teach users everything from the layout of the keyboard and operation of the printer to Boolean logic and the concept of controlled vocabulary. Great amounts of staff time are spent at a user's side discussing search strategy, downloading capabilities. and where to go after obtaining bibliographic citations from the CD-ROM, as well as unjamming printers, changing ribbons, and switching discs.

When considering the budgeting for CD-ROM's the hidden costs are numerous. In the continued process of staff training and user education, the cost of learning to use a CD-ROM product differs little from learning to use a new abstract or index. But with CD-ROM's there are budgetary considerations such as hardware obligations, including maintenance contracts, paper and ribbon costs, and security to consider. ${ }^{10}$

Despite these costs, the benefits derived from CD-ROM's or online access can be considerable. A Pennsylvania 
State University study of National Technical Information Service (NTIS) technical report usage from November 1989 to April 1990 saw a 183\% increase over this period due to the September 1989 installation of an NTIS CD-ROM in the Engineering Library. ${ }^{11}$ Comparable increases in the usage of government information are possible in other libraries and with other databases depending on factors, such as hardware and software searchability, the quality of user instruction, and the relative abilities of users to interface with the database.

Depositories selecting CD-ROM's and other electronic materials, even those not plagued by budgetary constraints, still require careful assessment of the quality of electronic products and their suitability for their users. Steven Zink asserts that professional literature reviews of CD-ROM products tend to be uncritical in their analyses of user interface and that there must be greater emphasis on ease of use in critiques of these products. ${ }^{12}$

Zink also maintains that this lack of substantive evaluation by librarians stems from their general unfamiliarity with software design or the rapid knowledge expansion of software ergonomics. Since software interfaces are designed for specific user groups instead of the divergent knowledge levels of library users, the awkward interfaces inherent in many CD-ROM's prevent their optimum utilization. ${ }^{13}$ Detailed and critical analysis of CD-ROM and other governmental, as well as commercial, electronic publications is crucial if effectual selection of electronic products is to be achieved.

Concern about the possible financial fallout incurred by depository libraries as a result of electronic products was expressed in OTA's 1988 report Informing the Nation, which advocated enhanced Federal financing as a means of offsetting this predicament:

...Congress needs to be aware that there may be additional costs associated with the introduction of certain electronic services, and assist depository libraries and GPO in designing and financing ways to make this information available to the public. ${ }^{14}$

Informing the Nation also recognized that the advent of electronic formats requires depositories to make new choices concerning their users' information needs and that acceptance of electronic products would be slower at smaller institutions due to shortages of required equipment, training, and financial support, as well as personnel and a wider range of personnel responsibilities. OTA also raised the unpleasant specter that the extra costs stimulated by electronic products might bring about the imposition of user fees, thus eroding or terminating a lengthy commitment to free and unimpeded access to government information. ${ }^{15}$

The prospect of charging user fees to obtain access to government information is abhorrent to documents librarians. A visible and emotional manifestation of this opposition was expressed at the Fall 1990 meeting of the Depository Library Council in Washington, D.C. An October 25 open forum at this gathering saw concern expressed over GPO's receptivity to depositories sharing the telecommunications costs of a Department of Energy (DOE) pilot project and the belief of many that this cost-sharing represented a seminal philosophical shift concerning the depository system and the dissemination and accessibility of government information. ${ }^{16}$

Several participants in the discussion over this issue maintained that GPO should be very cautious about changing the long-standing tradition of free public access to government information. The most visible display of audience sentiment was the presentation to the Depository Library Council of a petition signed by nearly 175 individuals reaffirming their commitment to the provision of government information through the depository library program without users or depositories incurring additional costs. ${ }^{17}$

Concern that emerging technologies will increase the gap between the "information rich" and "information poor" is not confined to government documents librarians. In March 1990, OTA's Critical Connections: Communication for the Future contended that "changes in the U.S. communication infrastructure are likely to broaden the gap between those who can access communication services and use information strategically and those who cannot." 18

Critical Connections correctly recognizes the problems involved in obtaining public access to government information. At the same time, though, it recognizes how electronic bulletin boards, such as the short-lived "The Capitol Connection” established in 1987 by the California State Assembly’s Utilities and Commerce Committee, and other databases can enhance societal knowledge of legislative and regulatory issues while fostering heightened public debate and participation. ${ }^{19}$

When issues of concern to depository libraries and national communications policy merge, Critical Connections recommends the following policy options: 
- Establishing government-affiliated institutional arrangements to promote the research, development, and deployment of communication and information technologies;

- Creating a governmental agency responsible for directing and coordinating the development of communication and information technologies;

- Establishing a Joint Communication Committee in Congress to enhance congressional coordination of communication issues; and

- Establishing an agency within the Executive Office of the President to devise a comprehensive communication policy and coordinate the activities of existing communication agencies. ${ }^{20}$

All of these ideas have merit though the possibility of their realization is questionable due to instinctive congressional and Executive Branch resistance to revising existing institutional jurisdictions and prerogatives. Obviously, the implementation of these programs would be monitored closely by depository librarians to assess their possible impact on the depository library program.

The impact of electronic products on depositories, such as Gray Library, must remain our more immediate concern. The disparities in financial resources between smaller depositories and their parent institutions and larger depositories and their parent institutions is likely to increase. This will probably increase the dependence of smaller depositories on regional depositories which will, in turn, incur additional financial and personnel costs. Such burdens may compel the regionals to cease providing free access to the smaller depositories which consequently may feel compelled to reconsider their status as depositories as resource sharing costs increase. ${ }^{21}$

There are no easy, popular, or cost-free solutions to this dilemma. Difficulties confronting smaller depositories increase exponentially when one incorporates depository library requests into Federal programs for social maintenance, national security, environmental protection, and numerous other public policy issues in the context of a several hundred billion dollar Federal budget deficit.

Since GPO and other Federal agencies apparently intend to make electronic products an integral part of the depository library program, the following steps should be considered. Optimal financial support should be provided to the regional depositories so they can acquire the equipment and recruit and train the personnel necessary to fulfill their responsibilities as primary providers of government information for their designated geographic regions.

Smaller depositories unable to provide the equipment and personnel required for effectual utilization and exploitation of electronic products should retain maximum possible access to these sources in paper and microfiche even if the regionals are only permitted to select these sources in electronic format.

GPO should also strive diligently to see that agencies and departments furnishing these products achieve maximum format standardization and compactness in order to save depositories from purchasing excessive and unnecessary hardware and software. This should also be done in order to minimize the time spent by personnel-strapped depositories in reading unnecessary system documentation and explaining multitudinous search strategies to users with divergent levels of computer literacy. This may require the enactment of congressional legislation and the implementation of effectual regulatory enforcement.

Congress should also consider revisions in 44 USC 1903 to recognize the divergent abilities of depositories to fulfill their statutory responsibilities in this era of increasingly electronic government information resources. Such legislation consequently must recognize that some government information will be inaccessible to smaller depositories. ${ }^{22}$ Recognition of these divergent capabilities should also be incorporated into the Depository Library Manual, Instructions to Depository Libraries, and future GPO depository inspections.

The depository community must also recognize that, in an era of mammoth and unremitting Federal budget deficits, maintaining free and unimpeded access to government information on a comprehensive scale, though a noble ideal worth striving for. is an unrealistic public policy option absent compelling public pressure for its perpetuation. Pragmatic recognition of this unpleasant fact should not diminish the depository community's commitment to providing optimal possible access to government information. Instead, it should force documents librarians to recognize that we are just one of multitudinous interest groups competing for a share of increasingly scarce Federal appropriations. Documents librarians must also recognize the increasing prevalence of user fees in other aspects of librarianship and information provision and adjust accordingly in this era of fiscal stringency. This must be done even 
as we hope for presidential and congressional leadership, coupled with popular support, for taking the painful steps required for the restoration of national financial probity and retaining free and unimpeded access to government information.

Meanwhile, smaller depositories, such as Gray Library, will have to get by as best as they can through the creative use of their own resources and increasing reliance upon their regional depositories for technical support and resource sharing. Documents librarians must recognize as other librarians do that not all collections are or can be equal and that each selective depository collection must build its strengths in the areas of greatest relevance and concern to its respective constituency.

Whatever the resolution of the debate over automation and access to electronic government information is, we cannot become so excessively absorbed by technological innovation and its consequences that we forget that our users see, and will see for the foreseeable future, their information needs best fulfilled in paper format. ${ }^{23}$ Depository librarians should also remember that they maintain stewardship over information and ideas of momentary and perpetual concern individually and collectively affecting past. present, and future generations. It would be particularly tragic if depository librarians permitted present interest and concern over automation to overcome their primary objective as serving as information-access facilitators to our respective constituencies regardless of their background, status, or technological sophistication.

\section{NOTES AND REFERENCES}

1. For the purposes of this study, smaller depositories are defined as those selecting $50 \%$ or fewer of GPO's selections. According to Peter Hernon. Charles R. McClure, and Gary R. Purcell. GPO's Depository Library Program: A Descriptive Analysis (Norwood. NJ: Ablex Publishing Corporation, 1985). pp. 63-64. this category in 1984 encompassed $75.4 \%$ of depositories with 5 I\% of these selecting $25 \%$ or less of GPO's selections. This same study also mentions that $81.7 \%$ of surveyed depositories were then staffed by one or fewer professional librarians, $76.9 \%$ by one or fewer paraprofessionals. and $84.1 \%$ by two or fewer student assistants.

2. Texas, Legislative Budget Board, Performance Report to the $72^{\text {nd }}$ Legislature January 8, 1991 (Austin: Legislative Budget Board, 1991). p. 58.

3. See Texas, Comptroller of Public Accounts, Fiscal Notes (April 1991). p. 1. and Fiscal Notes (January 1991). pp. 2-4, 6.

4. Texas, Senate Education Committee, Status of Academic Research Libraries at Texas Public Colleges and Universities, Prepared by Deborah L. Greene (February 1991). pp. I. 9, 13. This document may be obtained from the Texas Senate Education Committee. P.O. Box 12968. Austin. TX 78711 and was also distributed to academic libraries throughout Texas.

5. ibid., p. 14.

6. Ibid., p. 20. Senate Bill 933 introduced during the 72nd General Assembly seeks to remove libraries from state purchasing requirements. Its status at the time of writing is uncertain.

7. Government Printing Office, Administrative Notes: Newsletter of the Federal Depository Library Program, 12 (January I5, 1991): 4-5.

8. "Project Hermes to Distribute Supreme Court Opinions to Depository Libraries." Administrative Notes: Newsletter of the Federal Depository Library Program (November 30. 1990): I.

9. Congress, Office of Technology Assessment, Informing the Nation: Federal Information Dissemination in an Electronic Age (Washington, DC: GPO, 1988), p. 134.

10. Boyd Childress and Marcia L. Boosinger, "Staff and User Training for CD-ROM at Auburn University." pp. 83-84 in Public Access CD-ROM's in Libraries: Case Studies, Edited by Linda Stewart. Katherine S. Chiang. and Bill Coons (Westport, CT: Meckler Corporation. 1990).

11. Linda R. Musser and Thomas W. Conkling, "Impact of NTIS CD-ROM on the Use of a Technical Report Collection,” College \& Research Libraries News, 52 (February I991): III.

12. Steven D. Zink, “Toward More Critical Reviewing and Analysis of CD-ROM User Software Interfaces." CDROM Professional: The Magazine for CD-ROM Publishers and Users, 4 (January 1991): 16-17. 
13. Ibid., pp. 17-18.

14. Informing the Nation. pp. 16,150.

15. Ibid., pp. 155, 150-151.

16. Administrative Notes: Newsletter of the Federal Depository Library Program, 12 (February 28, 1991): 23-24. and personal recollection of this meeting.

17. Ibid., pp. 24-25.

18. Congress. Office of Technology Assessment. Critical Connections: Communications for the Future (Washington, D.C.: GPO. 1990), p. 11.

19. Ibid., p. 169.

20. Ibid., pp.345-346, 369, 376.

21. Informing the Nation, p. 150.

22. See Leo T. Sorokin, "The Computerization of Government Information: Does It Circumvent Public Access under the Freedom of Information Act and the Depository Library Program?,” Columbia Journal of Law and Social Problems, 24 (Spring 1991): 279, 295, for additional recognition of this exigency.

23. For corroboration of this within a government documents context see David Tyckoson. "Format., Usage, and Patron Preference for Information Sources." Technicalities, 8 (August 1988): 5. See also Arthur C. Tannenbaum, “Microforms and Users’ Feelings,” Microform Review, 13 (Summer 1984): 180. 